Journal of Engineering Sciences, Assiut University, Vol. 36, No. 6, pp.1347- 1360, November 2008

\title{
ASSESSMENT OF DIFFERENT TRAFFIC MANAGEMENT SCENARIOS USING MICROSCOPIC SIMULATION: A CASE STUDY
}

\author{
Jamil A. Naji \\ Civil Engineering Department, Faculty of Engineering, Sana'a University, \\ P.O. Box 14166, Sana'a, Yemen. \\ Email: jamil.abdulrabb@gmail.com
}

(Received September 20, 2008 Accepted October11, 2008)

\begin{abstract}
This paper presents the results obtained from microscopic traffic simulation study conducted to evaluate different traffic management scenarios (alternatives) for congested links in the capital city of Sana'a. The main objective of implementing simulation technique is to assist decision makers to select the most suitable solution to manage the problem of traffic congestion in effective and scientific manner and less cost for one of the busiest roads in the capital city of Sana'a.

Different real-life implementations of four types of traffic management scenarios were carried out. This includes Do Nothing, convert curb parking lane to effective traffic lane, waving/shifting public traffic vehicles (microbuses) to other routs outside the studied road and redesign the traffic signals. The Do Nothing scenario was considered as control/reference scenario. The improving or worsening due to implementation different scenarios was measured by comparing results from studied scenarios to that of the reference scenario.

Results were extracted from the simulation output reports and the selection of the most suitable scenario was based on a set of quantitative evaluation criteria. This includes delay time, travel time, flow, speed and fuel consumption.

Based on the criteria used the succeed scenario was recommended for implementation. The scenarios being most effective were converting the curb parking lane to effective traffic lane and shifting public microbuses to other routs. Although there is no significant difference between these two scenarios, the first one was recommended due to its simplicity, lower cost of implementation and convenience to road users.
\end{abstract}

KEY WORDS: microscopic traffic simulation, traffic congestion, delay time, travel time, flow and speed.

\section{INTRODUCTION}

The continuous increase in automobile traffic on road networks led to serious congestion problems in developing and developed cities, especially in cities with high growth potential. The most direct approach to reduce congestion is through infrastructure modifications by adding new lanes and bridges, which is by far the most expensive solution. There are other solutions that focus on improving the efficiency of 
the existing infrastructure such as operational modifications, better incident management and implementation of intelligent transportation system [1]. Thus, the focus in solving transportation problems is shifting to improving operational efficiency of existing networks. In developed countries, regulations require that all changes in the existing systems have to be checked for operational efficiency before field implementation [2]. The most suitable technique that can measure the operational efficiency of the existing infrastructure is the simulation. Traffic simulation is considered as the most practical and cost effective method to compare alternatives to achieve the most appropriate traffic management solution [1]. Moreover, traffic simulation has emerged as an important evaluation tool for intelligent transportation system strategies in recent years. It is widely used to perform traffic operations analysis and evaluate the merits of new traffic control and management technologies [3].

Traffic simulation as defined by Whol and Martin [4] and Drew, D.R. [5] is a dynamic representation of some part of the real world achieved by building a computer model and moving it through time. In traffic simulation, mathematical models are applied to predict the system performance based on representation of individual events in space and time and reflects the random nature of traffic. The heart and soul of the microscopic traffic simulation is the car-following, gap-acceptance and lane-change logic [2].

Based on the literature, traffic simulation has been in use for management purposes since the early 1950's. However, the flourishing of traffic simulation started recently due to the development in technology and programming tools. Such development has helped to produce more sophisticated software for use in complicated traffic and network conditions [6] and [7].

The problem of traffic congestion is one of the major problems in many developing countries with no exception to Yemen. Being the largest urban center in the country the problem in the capital city of Sana'a is becoming intolerable. The problem is dealt with practicing trail and error solutions without any scientific background. The use of traffic simulation technique has not introduced to the country so far.

\section{OBJECTIVE OF THE STUDY}

The main objective of this study is to introduce traffic simulation technique to the related agencies in the country by implement microscopic traffic simulation to evaluate various traffic management scenarios for alleviating traffic congestion existing on the western inner ring road in Sana'a city and to select the most suitable solution that can be adopted to reduce traffic congestion, enhance traffic flow, speed, travel time and gain other associated benefits such as reduction in fuel consumption and traffic emissions.

\section{BACKGROUND ON NETWORK DEVELOPMENT AND TRAFFIC CONGESTION IN SANA'A}

Old Sana'a, the core of the ancient urban agglomeration, was built long before the introduction of motor vehicles. Therefore, most of streets in the old part of the city were designed to pass packed camels. Such design provides a network mainly comprises of very narrow corridors. Thus, the street network, in the old part of the 
city, is currently dedicated mostly to pedestrians and connected to the new widespread city networks through gates.

The expansion of the city in the last decades has occurred from north to south direction due to limitation imposed by eastern and western chain of mountains. The type, width, alignment and density of Sana'a streets hold the historical stamp of its growth in stages. There are three main ring roads in the city. The inner ring road is the first and the oldest arterial surrounded the parts of the city that was built in the seventies. The width of this ring road is irregular and varies from place to another. The average width is ranging between 20 to $30 \mathrm{~m}$. The rapid growth of the city turned this arterial into a densely inner city street, as a result two other wider ring roads i.e. the 45 $\mathrm{m}$ ring road and the $60 \mathrm{~m}$ expressway were built around the old one.

The city of Sana'a has a population of about 1.95 million inhabitants according to the 2006 Yearbook statistics [8]. The traffic and transportation problems faced by the city are typical of fast growing cities, and with the non-existence of railway and public buses urban transport systems, the city depends heavily on normal size cars and public microbuses for transportation. This resulted in major congestion problems in most parts of the city.

The gap between the slow supply of roads to the increasing number of vehicles operating on roads is widening every year and making the problem increasingly unbearable throughout the city network, especially in the inner and central parts of the city. What is more, the problem is becoming worse due to other reasons such as the lack of appropriate maintenance programs to the network and vehicles, the nature and status of urban network especially that parts built before the eighties, unlawful onstreet parking practices, bad operation and driving practices from the public and microbuses trafficking.

The congestion problems are typically tackled by dealing with each site individually and by implementing trial and error solutions. Such practices waste time and limited funds. This situation emphasis the importance of using appropriate and scientific technique to deal with congestion problems in the city and traffic simulation is the suitable nominated technique.

\section{THE METHODOLOGY}

In order to achieve the objective of this study, a work program similar to that depicted in Fig. 1 was adopted. The figure explains, in short, the different steps of the followed work away from typical narrative description.

\section{THE STUDY AREA}

\section{The Roadway}

The road under study is a part of the inner ring road, the western part, it consists of six links and seven major intersections, see Fig. 2. The total length of the road is about 2.35 kilometer. The components of the cross section are, in average, $21 \mathrm{~m}$ paved roadway, $1.25 \mathrm{~m}$ median width and sidewalks with average width of $2 \mathrm{~m}$ each side.

Most of intersections are 4-leg type and their layout is varying considerably. A wide range of distance variation between consecutive intersections along the road is 
existed as indicated in Fig. 2. The distance is ranging between $700 \mathrm{~m}$ and $250 \mathrm{~m}$ with average value of $290 \mathrm{~m}$. This parameter has impact on traffic management strategies and type of solutions to propose e.g. no possibility of using grade separation due to space limitation. Therefore other management strategies should be considered.

\begin{tabular}{|c|c|c|c|}
\hline \multicolumn{4}{|c|}{ Objective of the study } \\
\hline \multicolumn{4}{|c|}{ 几 } \\
\hline \multicolumn{4}{|c|}{ Site selection and field data collection } \\
\hline \multicolumn{4}{|c|}{ 凸 』 } \\
\hline \multicolumn{2}{|c|}{ Data related to geometry of road } & \multicolumn{2}{|c|}{ Data related to traffic } \\
\hline \multicolumn{2}{|l|}{ 几 } & \multicolumn{2}{|c|}{ П } \\
\hline \multicolumn{4}{|c|}{ Simulator used and calibration process } \\
\hline \multicolumn{4}{|c|}{ 几 } \\
\hline \multicolumn{4}{|c|}{ Criteria of evaluation (delay \& travel time, speed, flow \& fuel consumption) } \\
\hline \multicolumn{4}{|c|}{$\llbracket$} \\
\hline \multicolumn{4}{|c|}{ Input data to simulator and running different scenarios } \\
\hline 凸 & 凸 & 几 & 几 \\
\hline $\begin{array}{l}\text { Scenario 1: DO NOTHING } \\
\text { (CONTROL SCENARIO) }\end{array}$ & Scenario 2 & Scenario 3 & Scenario 4 \\
\hline \multicolumn{2}{|l|}{ 几 } & \multicolumn{2}{|l|}{ 几 } \\
\hline \multicolumn{2}{|c|}{$\stackrel{\text { Comparing results }}{\rightleftarrows}$} & \multicolumn{2}{|c|}{ Results } \\
\hline \multicolumn{4}{|c|}{ Analysis \& evaluation process and selection of best scenario } \\
\hline \multicolumn{4}{|c|}{$\llbracket$} \\
\hline \multicolumn{4}{|c|}{ Conclusions and recommendations } \\
\hline
\end{tabular}

Fig. 1 Work Methodology

Most of intersections are equipped with isolated traffic signals, some of them non-operational due to lack of maintenance. The operating signals run independently and need maintenance. The current cycle length in some intersections is greater than 120 seconds. Extended cycle length (beyond 2 minutes) is usually adopted at congested intersections and flags the need of other solutions that focus on improving the operational efficiency of the existing network.

Even though the study area is representing small area in Sana'a city, it is a suitable representative type of congested areas due to its location between the two university campuses. Actually, the road is serving not only the university campus but also other residential areas with high population densities. 


\section{The fleet and public transport:}

Traffic fleet using the road under study is consisting mainly from small cars such as passenger car, pick up, microbus and similar. The only type of tracks that use the road is light truck, six tires and two axles (6/2), since heavy trucks are not allowed to use it. The only mode of urban public transport system in Sana'a is a fleet of private microbuses (7-11 seats) and small portion of medium buses (21 seats). This fleet is run by individuals and no other mode of public transport run by government or private companies. Therefore, the high share of microbus public transport vehicles is easily noticed. The share of this mode of traffic is account for about $30 \%$ of total traffic using the road under study.

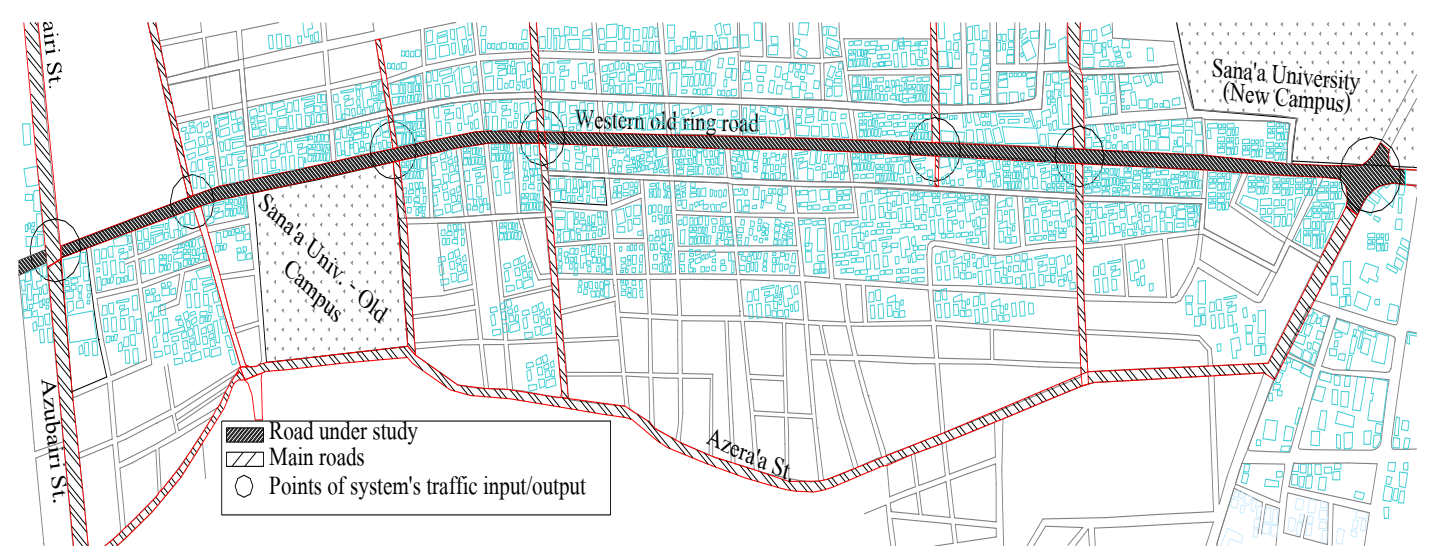

Fig. 2: The study area

\section{INVESTIGATED SCENARIOS}

This study has implemented four different traffic management scenarios as indicated below:

- Scenario1: Do Nothing (current situation - i.e. two effective traffic lanes, one curb parking lane and existing signals timing and phasing). This scenario was used as a reference/control scenario.

- Scenario 2: Lane addition by converting curb parking lane to effective traffic lane.

- Scenario 3: Waving/shifting the public traffic - the microbuses - to un-congested minor routs outside the system (outside the inner western ring road).

- Scenario 4: The conditions of this scenario is similar to that of scenario 1 with the exception that the existing signals timing and phasing were revised based on data collected from sites.

\section{DATA COLLECTION}

The field data required for microscopic traffic simulation include data related to the geometry of road and intersections in addition to traffic demand data. The geometry and border the area under study was obtained from drawings issued for the area by the general authority of water and sanitation. A field checks were made for the geometry 
of the intersections using field survey with total station equipment. The data obtained from field survey were fed into three dimensional software and all geometric elements were extracted and used for simulation purpose. The geometrical elements include the shape of road, number of sections, number of lanes in each section, the length of each section, lanes width, medians width, storage lanes dimension, grades ...etc.

Traffic demand data required by simulator needs to be defined by $\mathrm{O} / \mathrm{D}$ matrices or by the traffic flows at input sections and its turning proportions. In this study, the traffic demand on the road was represented by flow at sections input. Thus, traffic demand was obtained by direct count during peak hour, which was found to be between 11.30 am and $12.30 \mathrm{pm}$. The count was made at sections inputs and classified to traffic volume by vehicle type and turning movement to suit the simulator requirements.

\section{SIMULATOR USED AND CALIBRATION PROCESS}

AIMSUN "Advanced Interactive Microscopic Simulator for Urban and non-urban Networks" has been used in this study. It is one of the well known simulators that have been emerged during the last decades. It consist of a set of microscopic simulating modules providing a powerful, integrated platform for modeling a complete range of real world traffic and transportation problems. It includes simulation of varying driver and vehicle characteristics and presents its output as a real time visual display [9].

AIMSUN calibration, in general, is an iterative process in which appropriate parameters are adjusted in order to ensure that the model reflects as accurately as possible the existing road conditions. The calibration mainly involves the alteration of global parameters like simulation step \& reaction time and parameters related to traffic flow models and vehicle parameters such as speeds, minimum distance between vehicles. Previous studies showed that the most important variables for calibration are headway and reaction time [10] and [11].

Based on the available traffic data and existing road geometry, a volume based calibration was accomplished in several trial and error stages and the most suitable values of the parameters were selected and presented in Table 1 . These values gave acceptable match between simulated results and the corresponding field data. The calibration was made on a data different from that used in running the simulator for the purpose of evaluating the scenarios under study.

The reason for selecting volume based calibration procedure was its successful implementation for calibrating AIMSUN in earlier studies [12] and [13].

Table 1: The parameters obtained from the calibration process

\begin{tabular}{|crr|crr|}
\hline Global parameters: & Value & Unit & Vehicle type parameters: & Value & Unit \\
\hline Driver's reaction time & 1.5 & $\mathrm{sec}$ & Max. mean desired speed & 40 & $\mathrm{kph}$ \\
Simulation step & 0.5 & $\mathrm{sec}$ & Min. distance bet. Veh. & 1 & $\mathrm{~m}$ \\
Queue up speed & 1.0 & $\mathrm{~m} / \mathrm{sec}$ & & & \\
Queue living speed & 4.0 & $\mathrm{~m} / \mathrm{sec}$ & & & \\
\hline
\end{tabular}




\section{CRITERIA OF EVALUATION}

AIMSUN provides different output such as flow rate, speed, density, travel time, delay time, fuel consumption and pollution emitted ...etc. The output can be specified at different levels of aggregation such as output for the whole system, for each section, for each turning movement and for every stream (set of consecutive sections).

In this paper, the four traffic management scenarios studied were evaluated based on system results of five different outputs. This include delay time per vehicle per kilometer (the difference between the expected travel time "under ideal condition" and simulated travel time), travel time (average time a vehicle needs to travel one kilometer inside the network), flow rate (average number of vehicles per hour that have passed through the network during the simulation period), average mean speed for all vehicles that have left the system and fuel consumption per all vehicles that have crossed the system.

The scenario that provides less delay and travel time, maximum speed and flow rate and less fuel consumption will be considered as the successful solution among the studied scenarios.

\section{RUNNING THE SIMULATOR}

Having setting the simulator, the next step was to feed the software with the needed input data. The input data required by AIMSUN is a simulation scenario and a set of other simulation parameters that define the experiment. The scenario is composed of four types of data: network description, traffic control planes, traffic demand data and public transport plan. The simulation parameters are fixed values that describe the experiment (simulation time, warm-up period, statistics intervals, number of replications ...etc) and some variable parameters used to calibrate the models such as reaction times and simulation step [9].

Since the simulation was run only for traffic during the rush hour, the input was limited to one control plan, one master control plan, and traffic demand during rush hour. No public transport plan was considered since the only mode of public traffic in the city is a fleet of microbuses owned by individuals without any public transport plan.

Each experiment was run for four replications to ensure statistical reliability and the periodic statistical results were recorded every 5 minutes intervals. The simulation period was one hour with 15 minute warm-up period to populate the network with vehicles and allow traffic conditions to stabilize before collection of statistics on performance. The distribution of the entries of vehicles to the system was assumed to be governed by exponential distribution.

The simulator was run several times according to the number of scenarios exercised. For each run, the inputs were adjusted to suit the exercised scenario.

\section{RESULTS}

As mentioned earlier, the results from AIMSUN can be specified at different levels of aggregation. In this study, the evaluation was made on system's results because such results give a panoramic picture for the performance of whole system rather than 
isolated sections. Scenario 1 was considered as a reference/control scenario and therefore the improvements or worsening in performance due to investigated scenarios were made by comparing its results with that obtained from the control scenario. The following sections describe and discuss the obtained results.

\section{Delay and Travel Time Results}

Fig. 3 and Fig. 4 show the trend of average delay time and travel time during the simulated hour for the four studied scenarios. The general trend in both figures is positive with different rates and this implies that delay and travel time increasing during the simulated hour. This might be attributed to the accumulation of traffic at intersections due to the failure of some traffic signals to discharge all stored traffic during the greens periods. The best improvement, in term of reducing delay time, was obtained from scenario 3 (waving public traffic - microbuses - to routs outside the studied road). Close results were obtained form scenario 2 (converting curb parking lane to effective traffic lane). Scenario 4 (re-design traffic signals) did not produce a significant improvement in term of reducing delay time along the road.

Noticeable improvement in term of travel time was gained from scenario 2 and 3 as indicated in Fig. 4. alternatives.

Results obtained prove that these two scenarios are superior among other

Statistical analysis using SPSS software was performed to check if the difference in the obtained delay/travel time values for the four scenarios studied are due to experimental error or due to the type of management (scenarios) proposed. One way Analysis of Variance (ANOVA) for the single factor model was used. The appropriate procedure for testing the differences of treatment means $\left(\mu^{\text {ss }}\right)$ is to check the following hypothesis [14]:

\section{The null hypothesis:}

$$
H_{0}: \mu_{1}=\mu_{2}=\ldots \ldots \ldots . .=\mu_{n}
$$

The alternative hypothesis: $\quad H_{1}$ : at least two means are not equal

For testing the previous hypothesis, ANOVA utilizes $F$ test in which the estimate of between-groups variance (SSR) is compared with the estimate of withingroups variance ( $S S E$ ) i.e., $F=S S R / S S E$. If the $S S R$ is considerably larger than $S S E$, then the value of the $F$ ratio will be higher, which indicates that the differences between the means are unlikely to be due to chance [15].

Results from ANOVA, Table 2 and 3, indicate that delay/travel time means are significantly different from each other at 5 percent significance level and these differences are due to the type of traffic management scenarios proposed for the studied site.

ANOVA results inform only about the presence of the differences among at least two means - as indicated in the alternative hypotheses shown above. It does not however inform about which means are significantly different from each other and which means are not. Therefore Scheffe Test was used to examine the difference among every pair of means. Results indicated that the means of delay and travel time from scenarios $2 \& 3$ are not significantly difference. Similar results for scenarios 1 and 4 were noticed as indicated in Tables 4 and 5 where statistically equal means were arranged in the same column. 


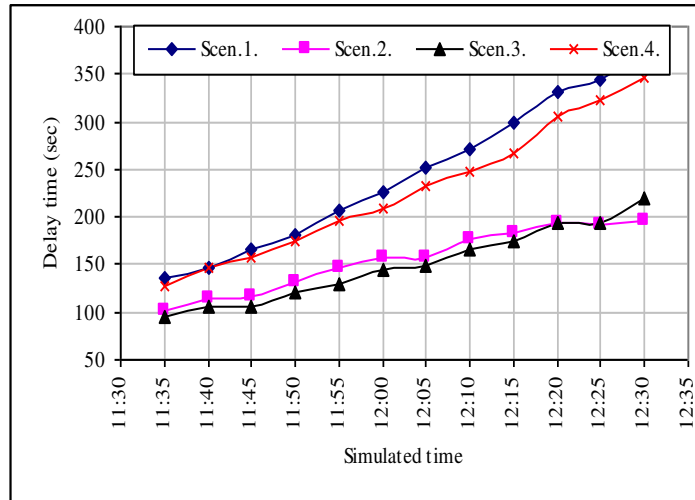

Fig. 3: Delay time for the different scenarios

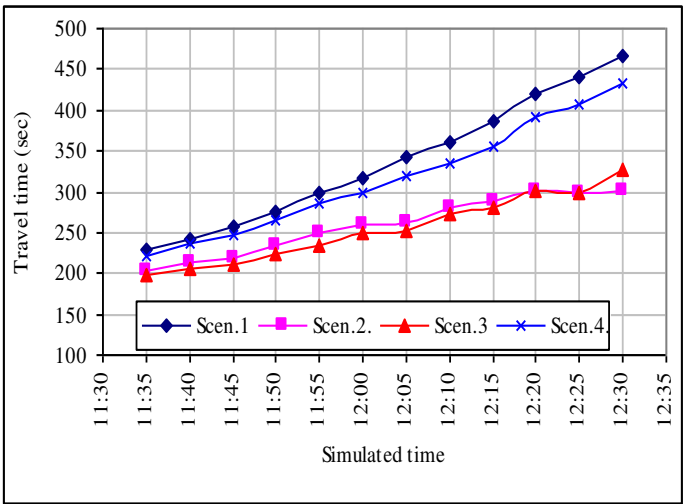

Fig. 4: Travel time for the different scenarios

Table 2: Analysis Of Variance (ANOVA) for delay time results

\begin{tabular}{lrcrcc}
\hline & Sum of Squares & df & Mean Square & F & Sig. \\
\hline Between Groups & 85670.373 & 3 & 28556.791 & 7.836 & .000 \\
Within Groups & 160347.116 & 44 & 3644.253 & & \\
Total & 246017.488 & 47 & & & \\
\hline
\end{tabular}

Table 3: Analysis Of Variance (ANOVA) for travel time results

\begin{tabular}{lrcrll}
\hline & Sum of Squares & df & Mean Square & F & Sig. \\
\hline Between Groups & 60649.582 & 3 & 20216.527 & 5.696 & .002 \\
Within Groups & 156164.703 & 44 & 3549.198 & & \\
Total & 216814.285 & 47 & & & \\
\hline
\end{tabular}

Table 4: Scheffe's test results for delay time

\begin{tabular}{|c|c|c|c|}
\hline \multirow[b]{2}{*}{ SCENARIO } & \multirow[b]{2}{*}{$\mathrm{N}$} & \multicolumn{2}{|c|}{$\begin{array}{l}\text { Subset for alpha }= \\
.05\end{array}$} \\
\hline & & 1 & 2 \\
\hline 3 & 12 & 149.8650 & \\
\hline 2 & 12 & 155.5000 & \\
\hline 4 & 12 & & 227.2875 \\
\hline 1 & 12 & & 245.0067 \\
\hline Sig. & & .997 & .915 \\
\hline
\end{tabular}

Table 5: Scheffe's test results for travel time

\begin{tabular}{crrr}
\hline & & \multicolumn{2}{c}{$\begin{array}{c}\text { Subset for alpha }= \\
\text {.05 }\end{array}$} \\
\cline { 3 - 4 } SCENARIO & $\mathrm{N}$ & \multicolumn{2}{c}{1} \\
\hline 3 & 12 & 254.4167 & \\
2 & 12 & 259.1667 & \\
4 & 12 & & 316.3200 \\
1 & 12 & & 336.4167 \\
Sig. & & .106 & .877 \\
\hline
\end{tabular}

\section{Flow Results}

Flow results for the four studied alternatives are presented in Fig. 5. The figure shows considerable fluctuation in flow during the simulation hour. The best improvement in flow was noticed in scenario 2 followed by scenario 3 where the curves of these two scenarios were well above the curves of other scenarios. This implies that these scenarios were better in term of improving traffic flow rates on the studied road. The gained benefits, in term of flow rate, at the end of the simulated hour were more than 1300 and 1220 vehicle per hour for scenarios 2 and 3 respectively. 
Results form ANOVA revealed that flow rates are significantly different at 5\% S.L as indicated in Table 6. Furthermore, Scheffe Test results showed that the means of flow rates in case of scenarios $2 \& 3$ are statistically equals. Similar results for scenarios 1 and 4 were obtained.

\section{Speed Results}

Fig. 6 shows the trend of speed of the four different scenarios studied. As shown in the figure, considerable increase in speed was noticed in case of scenario 2 and 3. However scenario 4 did not produce a significant improvement in the performance of traffic on the road. The gained increase in speed from scenario 2 and 3, at the end of the simulated hour, was about $34 \%$ compared to Do Nothing scenario.

ANOVA results explained that speed means are significantly different at 5\% S.L. Results from Scheffe Test showed that the means of speed in case of scenarios 2 $\& 3$ are statistically equals. Similar results for scenarios 1 and 4 were obtained.

\section{Fuel Consumption Results}

The effect of management type on fuel consumption was studied. Results are presented in Fig. 7. It is clear from the figure that the fuel consumption differ form scenario to another. The figure shows that best results, in term of saving in fuel consumption, was obtained from scenario 2 with average saving percentages of $28 \%$ (compared to Do Nothing scenario).

It is important to note that fuel consumption from scenario 3 was not presented in the figure because the simulator calculate fuel consumption while traffic inside the system. This is not true in case of scenario 3 since public traffic (microbuses) was moved outside the system in this scenario. The waved portion of traffic represents about $30 \%$ of total traffic and therefore, considerable reduction in fuel consumption was noticed in scenario 3. Thus introducing fuel consumption for scenario 3 in Fig. 7 may guide to misleading findings.

The inclusion of fuel consumption in the analysis was for the purpose of comparison scenarios 1,2 and 4 only. Results form ANOVA revealed that fuel consumption are significantly different at $5 \%$ S.L.

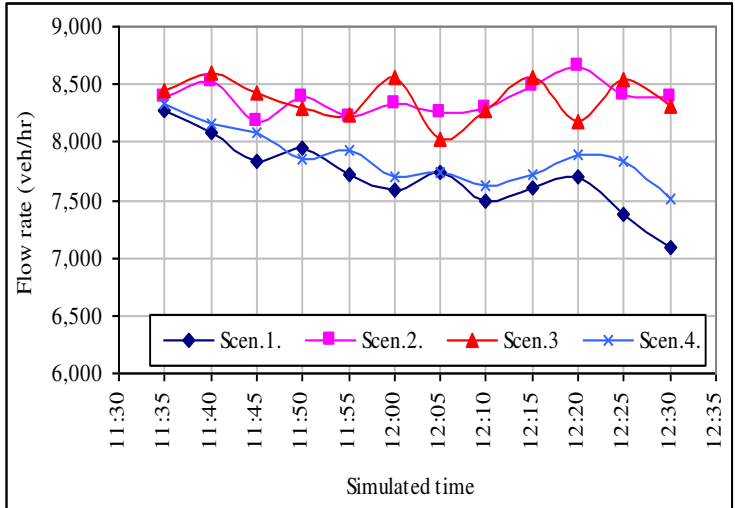

Fig. 5: Traffic flow for the different scenarios

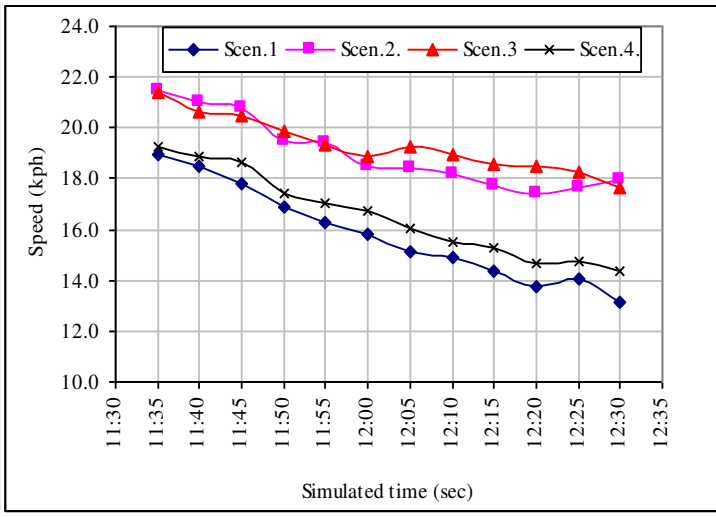

Fig. 6: Average speed for the different scenarios 


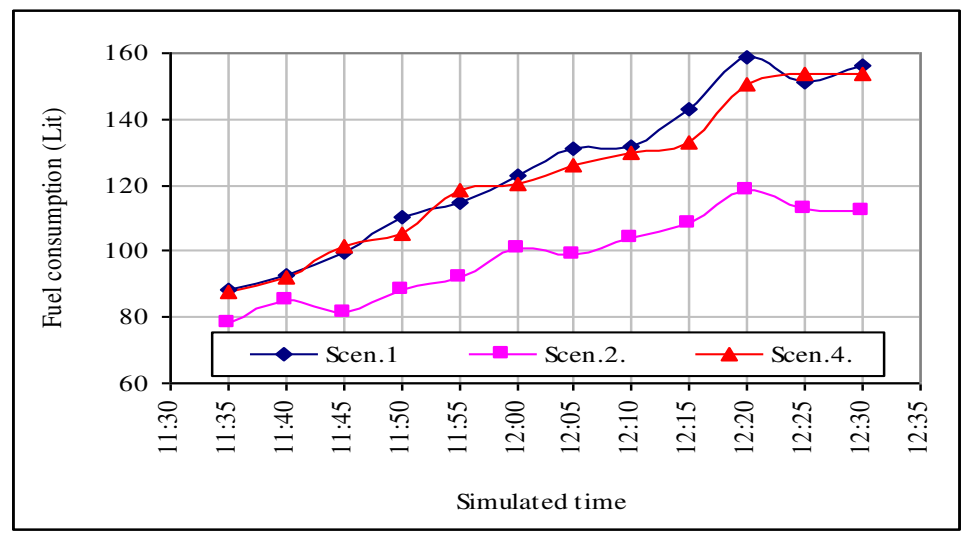

Fig. 7: Fuel consumption for studied scenarios

Table 6: ANOVA results for traffic flow

\begin{tabular}{lrcccc}
\hline & $\begin{array}{r}\text { Sum of } \\
\text { Squares }\end{array}$ & df & $\begin{array}{c}\text { Mean } \\
\text { Square }\end{array}$ & F & Sig. \\
\hline $\begin{array}{l}\text { Between } \\
\text { Groups }\end{array}$ & 1466779.000 & 3 & 488926.333 & 12.262 & .000 \\
$\begin{array}{l}\text { Within } \\
\text { Groups }\end{array}$ & 1754410.000 & 44 & 39872.955 & & \\
Total & 3221189.000 & 47 & & & \\
\hline
\end{tabular}

\section{CONCLUSIONS AND RECOMMENDATIONS}

Based on the results obtained from this study, following conclusions and recommendations has been devised.

- It is certainly advantageous to convert the curb parking lane into effective traffic lane (scenario 2). This will improve the flow on the road and therefore associated advantages will be gained such as increase the speed, reduction congestion, saving in fuel consumption and reduction in emissions. The magnitude of the improvements found from applying scenarios 2 was reasonably high to justify the implementation of this scenario; especially the cost of implementing this scenario is minimal.

- Although shifting the public traffic - microbuses - to new routs (scenario 3) has similar advantages to that gained in scenario 2, scenario 3 is not preferable from practical point of view because it may cause disturbances to road users, due to shifting traffic outside the familiar road, and also it may leads to some congestion and safety hazard in the new local routs.

- Re-design traffic signals and updating timing and phasing system (scenario 4) did not bring a significant improvement in the performance of traffic on the road.

- Traffic simulation is not only a cost effective and easy to use tool in traffic management process but also it is a method that provides an output with minimal effort. Therefore, similar studies are recommended to be conducted in large scale in the city of Sana'a. 
- Due to the great advantages that can be obtained from traffic simulation techniques, it is the time to adopt such technique in the Yemeni universities and related agencies such as Sana'a mayor office.

- Due to time and data collection limitations, the scope of the work was restricted to small study area and only four scenarios; however large areas and other different scenarios can be exercised in further studies.

\section{ACKNOWLEDGEMENTS}

I would like to express my gratitude to The German Academic Exchange Service (DAAD) who supported the author's visit to Germany during summer, 2007. I am deeply indebted to Prof. Dr.-Ing. Bernhard Friedrich, the director of the Institute of Transport, Road Engineering and Planning, University of Hannover (ivh) for his help, valuable hints and for providing a great environment during my stay in ivh. I have furthermore to thank all staff in the institute for their assistance. In particular I am obliged to Dr.-Ing. Stephan Hoffmann, Jannis Rohde, and Daniel Schmidt for their interests and support.

\section{REFERENCES}

1. Joy Bhattacharya and Ryota Horiguchi, (2005). Implementation of transportation management strategies using AVENUE for developing countries. http://www.transport.iis.u-tokyo.ac.jp/publications/2005-026.pdf

2. Haifeng Xiao, Ravi Ambadipudi, John Hourdakis and Panos Michalopoulos, (2005). Methodology for selecting microscopic simulators: Comparative evaluation of AIMSUN and VISSIM. Final report, Department of Civil Engineering, University of Minnesota, Center of Transport Studies, Intelligent Transportation Systems.

3. Adnan, M. A. and Fadhil, M. F. M., (2008). Traffic flow simulation with PARAMICS at on-Ramp expressway under different range of geometric design and various rang of traffic demand. The international conference on construction and building technology, Kuala Lumpur, Malaysia, June 16-20, 2008

4. M. Whol and B. V. Martin (1983). Traffic system analysis for engineers and planners, McGraw Hill, Inc.,

5. Drew, D.R. (1968). Traffic flow theory and control. New York: McGraw-Hill.

6. Matti Pursula, (1999). Simulation of traffic systems - An overview, Journal of Geographic Information and Decision Analysis, vol.3, no.1, pp. 1-8, 1999.

7. Anand Rajagopal, Dhingra S. L. and Pranay Singhi, (2002). Comparative evaluation of traffic management strategies using simulation. Civil Engineering Department, IIT-Bombay, Powai, Mumbai, India.

8. Ministry of Planning and International Cooperation, Central Organization for Statistics, Statistical year book, 2006

9. TSS - Transport Simulation Systems, (2005). AIMSUN 5.0 Microsimulator user's manual, Nov. 2005

10. Sarawut Jansuwan and Sorawit Narupiti, (2005). Assessment of area traffic control system in Bangkok by the microscopic simulation model, proceeding of the Eastern Asia Society for Transportation Studies, Vol. 5pp 1367-1378. 
11. Abdulhai, B., Sheu, J. and Recker, W. (1999). Simulation of ITS on the Irvine FOT area using Paramics 1.5, phase 1: Model calibration and validation, a report prepared by California PATH Program of the University of California.

12. Hourdakis, J., Michalopoulos, P.G. (2002). Evaluation of ramp control effectiveness in two cities freeways, Transportation Research Board, annual meeting, January 2002

13. Hourdakis, J., Michalopoulos, P.G. Kottommannil, J.V (2003). A Practical procedure for calibrating microscopic simulation models, Transportation Research Board, annual meeting, January 2003.

14. Montgomery, D. C. (1991). Design and analysis of experiments, $3^{\text {rd }}$ Ed., Wiley, New York.

15. Bryman, A., and Cramer, D. (1990). Quantitative data analysis for social scientists., Routledge, London.

\section{تقيم خيار ات (سيناريوهات) مختلفة لإدارة حركة المرور باستخدام المحاكاة الجزئية: دراسة مالة الأة حراتة}

تقدم هذه الورقه النتائج التي تم الحصول عليها من دراسـة محاكاه مروريه اجريت لغرض تقييم بدائل (سيناريوهات) مختلفة لادارة المرور على احد الطرق المزدحمه في العاصمة صنعاء. ان الهدف الرئيس

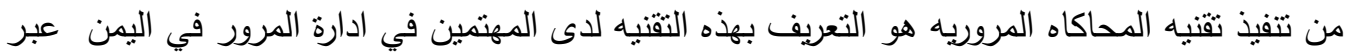
تطبيقها على احد الطرق في صنعاء ومن ثم اختيار الحل الانسب لادارة حركة المرور على الطريق بطريقة علميه وبأقل تكلفة.

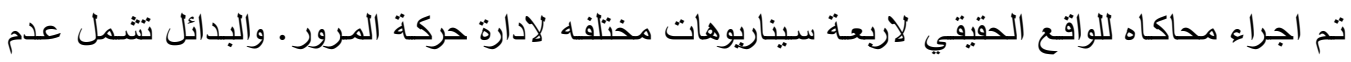

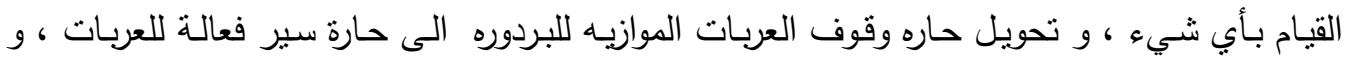
تحويل حركة المركبات العامة (حافلات صغيرة) الى طرق خارج الطريق المدروس ، و السيناريو الاخير مشابه للسيناريو الاول مع اختلاف وحيد وهو اعادة تصميم الإثارات الضوئيه. وقد تم استخدام السيناريو

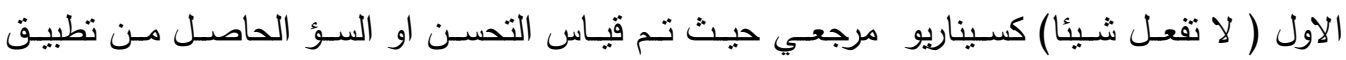

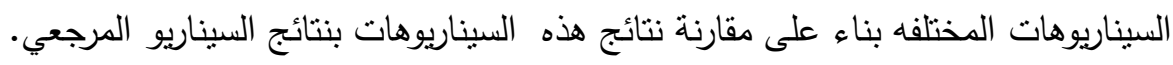

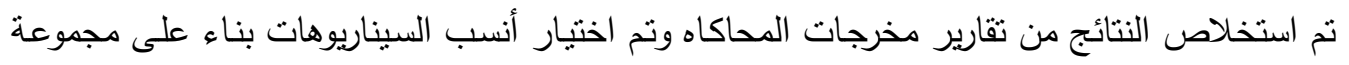

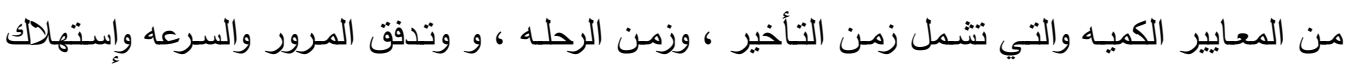

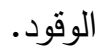

واستتادا الى المعايير السابقه تم اختيار البديل الانسب حيث وجد ان السيناريوهات الاكثر فعالية في

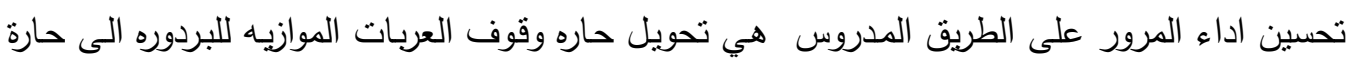


سير فعالـة للعربـات او تحويل حـافلات نقل الركاب العامـه الصـغيره الـى طرق اخرى خـارج الطريق

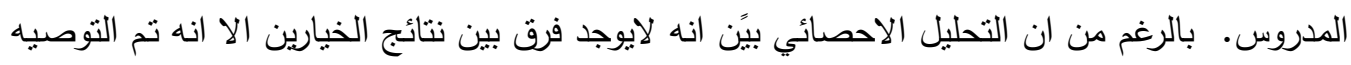

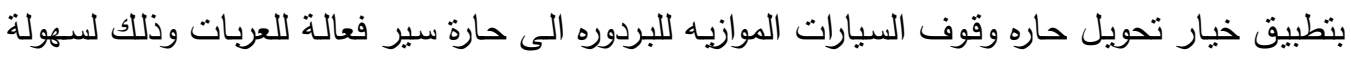
وقلة تكلفة تتفيذه و كذا لملائيته لمستخدمي الطريق. 